\title{
Innovative passive and active countermeasures for near side crash safety
}

\author{
Javier Luzon-Narro ${ }^{1,2}$, Carlos Arregui-Dalmases ${ }^{2,3}$, Luis M Hernando ${ }^{4}$, Emiliano Core ${ }^{5}$, \\ Alberto Narbona ${ }^{6}$, Carlos Selgas ${ }^{7}$ \\ ${ }^{1}$ Centro Técnico de SEAT, S.A. (Spain) \\ ${ }^{2}$ Universitat Politècnica de Catalunya - Barcelona Tech \\ ${ }^{3}$ University of Virginia Center for Applied Biomechanics \\ ${ }^{4}$ Fundación CIDAUT \\ ${ }^{5}$ TRW Automotive \\ ${ }^{6}$ GESTAMP \\ ${ }^{7}$ GRUPO ANTOLIN
}

\begin{abstract}
This research presents six simultaneous innovative occupant near side lateral impact protection concepts including a dynamic door, high-volume side airbag, a large external airbag that covers doors, sill and B-pillar of the struck vehicle and other concepts for increasing the distance between the occupant and the door panel (active armrest, inflatable door beam and moving seat). All systems are based on pre crash detection of the impact and are activated as soon as 80ms before the impact. This paper details the task of integrating these systems into a vehicle using FE models, sled tests, and full scale crash tests. Sled test dummy responses were compared with and without the countermeasures.
\end{abstract}

Keywords - Side impact, Pre-Crash, external airbag, seat, pyrotechnic, lateral protection.

\section{INTRODUCTION}

Approximately forty percent of all crashes are side impacts [1]. Side impacts involving US passenger cars accounted for $33.4 \%$ of fatalities and $28.1 \%$ of all injuries (Ref Based on the Traffic Safety Facts 2000-2009, published by NHTSA, a compilation of Fatality Analysis Reporting System (FARS) and General Estimates System (GES) data). According to national datasets of the UK, France and Sweden from the year 2005, side impacts typically represented $32.7 \%$ of all fatalities [2]. In previous epidemiologic research side impacts was found to be twice as likely to be fatal as frontal impacts [3].

For front seat passengers, head injuries are the most prevalent (28 percent of AIS 2+ injuries) followed closely by chest injuries ( 22 percent). Lower extremity and pelvis injuries accounted for 19 percent. However, for more severe AIS 4+ injuries, chest injuries were the most common (41 percent) followed by the head (36 percent) and the abdomen (31 percent) [4].

The average speed in side crashes with injured occupants (any severity), according the Spanish indepth accident database DIANA is $68 \mathrm{~km} / \mathrm{h}$ [5]. Also the US NASS-CDS database shows a high number of AIS $3+$ injuries for $\Delta \mathrm{V}$ ranging between $33-40 \mathrm{~km} / \mathrm{h}(26.6 \%)$, that corresponds to a crash speed higher than $50 \mathrm{~km} / \mathrm{h}$. According to that, the potential of the presented countermeasures under more severe conditions were also evaluated, through one test at $60 \mathrm{~km} / \mathrm{h}$ in addition to $50 \mathrm{~km} / \mathrm{h}$.

One of the main reasons that near side impacts are so injurious is the limited pre crash distance between the occupant and the vehicle side structures. This precondition, combined with high intrusion velocities, results in a short time between the beginning of the collision and the moment when the intruding door panel contacts the occupant. This limits the range and performance of possible passive safety countermeasures such as thorax-pelvis side airbags, head airbags, padded door panels.

However, advances in sensors systems that can deploy countermeasures in advance of an impending impact liberate countermeasure development from existing space and time constraints. For example the EC funded APROSYS PreVENT system used a pre impact detection systems based on cameras and radars which deployed structural reinforcing members in order to limit intrusion and intrusion velocity [6].

The research presented here describes countermeasures that exploit this new pre impact sensing capability. The six countermeasures assessed in this research are presented in Figure 1. They are 
divided into three areas: Structural behaviour (dynamic door, inflatable door side impact beam, external airbag), interior (active armrest, moving seat) and restraint systems (high-volume side airbag).

\section{Description of the different pre-impact systems}

\section{Dynamic door}

This device creates a controlled displacement of the door outwards from the vehicle. This movement is achieved by the use of three pyrotechnic actuators, located in different parts of the door.

This concept has two goals: to increase the internal clearance between occupant and door providing additional space for the deployment of side airbag, and to use the actuators themselves as energy absorbing elements, so that they effectively help to reduce the intrusion velocity.

To ensure proper function, the system has to be associated with stroke limiter and a door guiding device, ensuring that the door returns back to its original position during crash.

\section{Inflatable door side impact beam}

This optimized side impact beam is formed by 2 sheets of stamped Ultra High-Strength Steel (UHSS). By means of a pyrotechnical gas generator, the beam can be inflated just before the impact, achieving an increase of the bending stiffness due to the increase of cross-section, therefore the moment of inertia and the internal pressure. Its main goal is providing a reduction in terms of intrusion velocities.

\section{External airbag}

A large airbag of 2901 which deploys from the rocker panel, cushions the doors, sill and B-Pillar up to the vehicle belt line. This airbag mitigates the energy of the collision and reduces the intrusions and deformations in the struck vehicle.

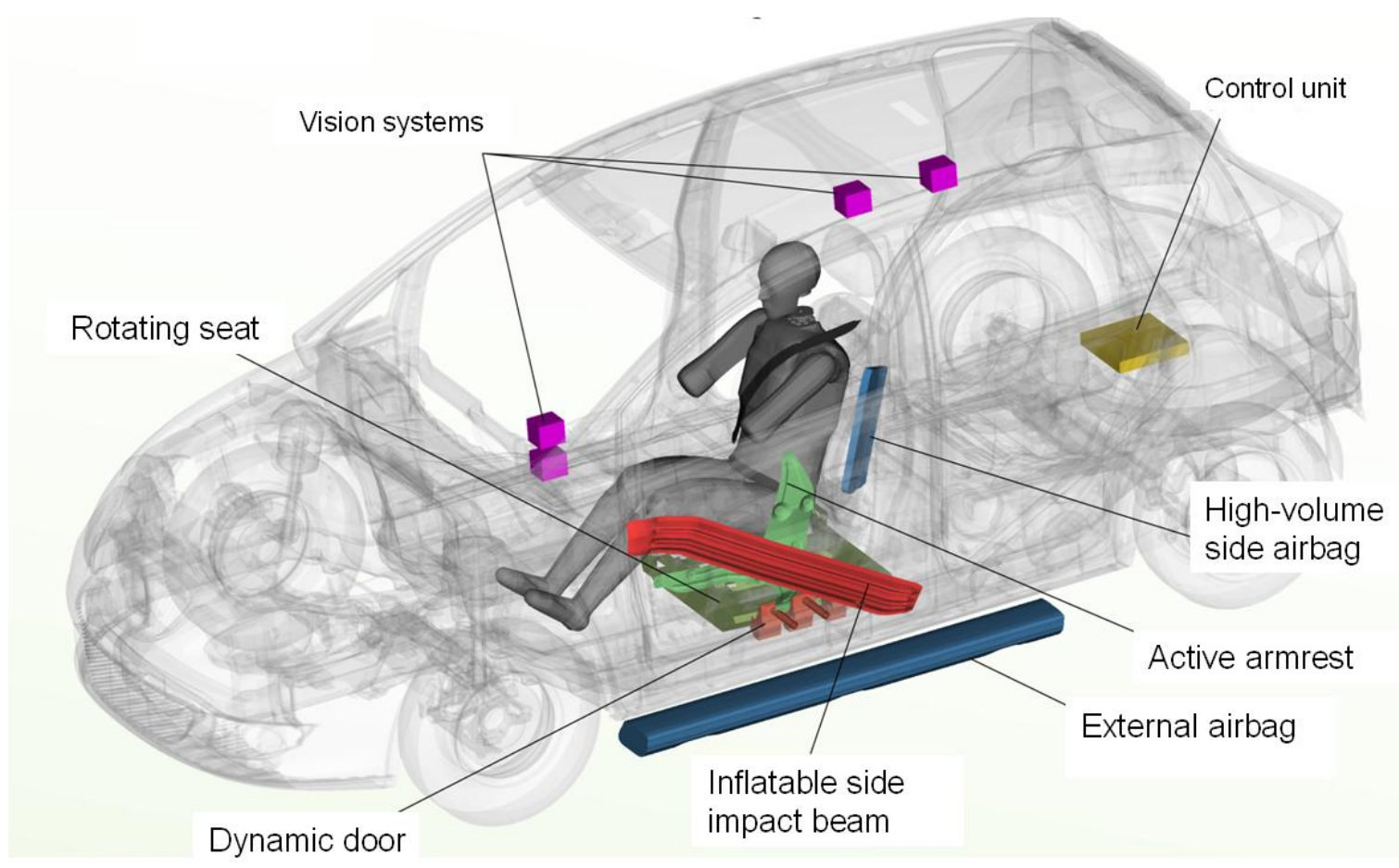

Figure 1. Pre-crash side impact countermeasures 
A new door trim panel morphology was designed to include an active armrest with a pyrotechnical actuator located at the base of the door. The trigger signal displaces the armrest away from the occupant and therefore increases the clearance between the occupant and the door $30 \mathrm{~mm}$, a $20 \%$ increase. This strategy also reduces the aggressiveness of the geometry of the door panel.

\section{Rotating seat}

This system produces inboard occupant movement by rotating the seat base in the anchorage zone through eight pyrotechnic actuators. The tilt of the occupant increases the distance between the occupant and the door (Fig 2). A dual pretensioning safety belt integrated in the seat was mounted, to improve coupling between occupant and seat.

\section{High-volume side airbag}

A high-volume side airbag of 421 . designed to fill the increased available volume between the occupant and the door panel once the other systems have been deployed.
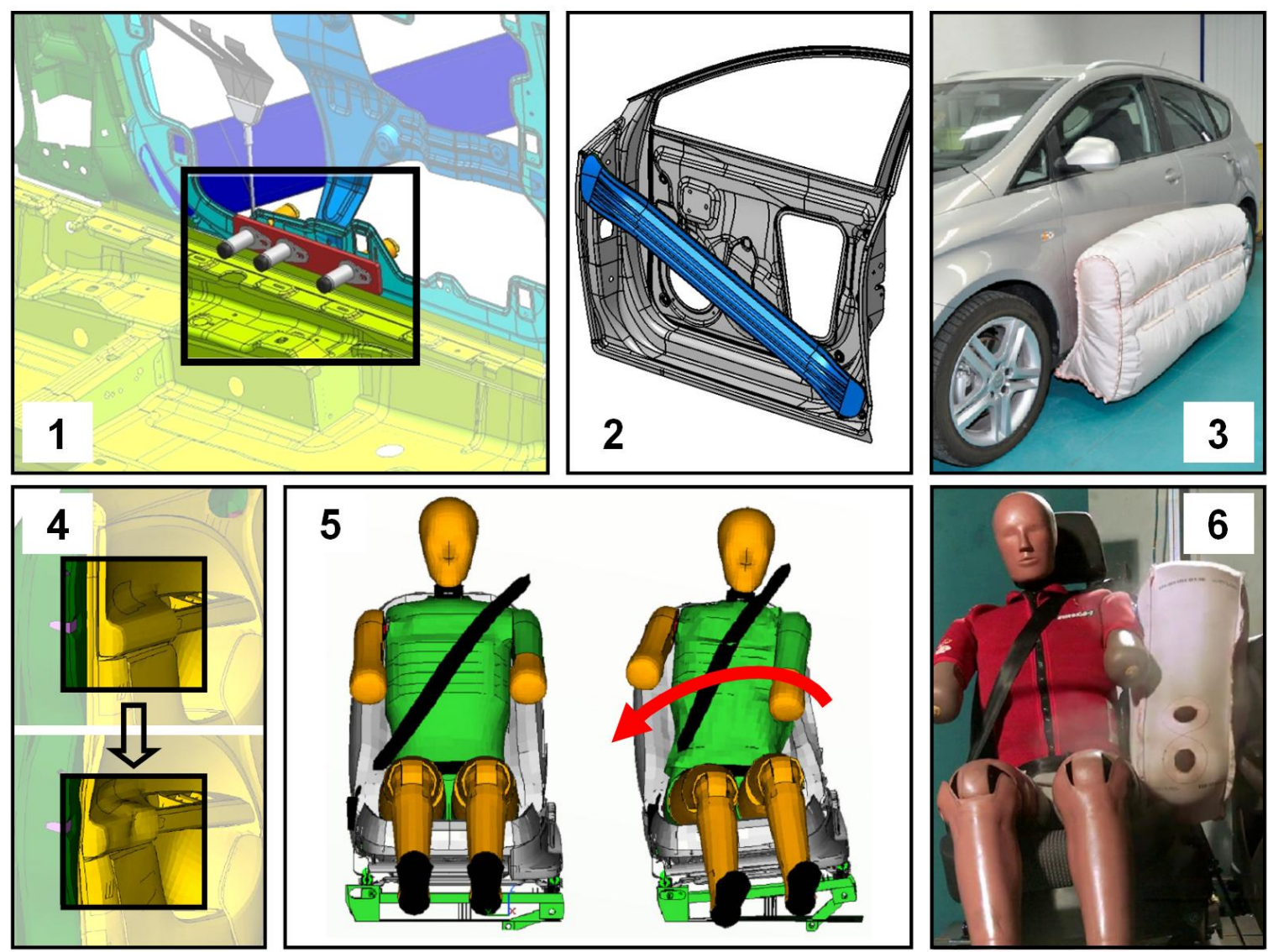

Figure 2. Detail of the side impact countermeasures: 1. Active door opening system. 2. Inflatable door beam. 3. External airbag. 4. Active armrest. 5. Rotating seat. 6: 3D Side airbag 


\section{METHODS}

\section{Experimental procedure}

The validation methodology of the systems was divided into two groups of tests: First the tests involving the different countermeasures were carried out independently, and once the performance for the six sub-systems was satisfactory, a reference vehicle was prepared for the integration and validation of all the countermeasures to act simultaneously.

The integration process of the systems includes FEM simulation, sled tests as well as full scale crash tests with the sample vehicle. Firing times of each of the systems were defined via simulation and validated in the full scale crash. The final activation sequence of the systems can be seen in Figure 3 . The methodology used to obtain this chart is described below.

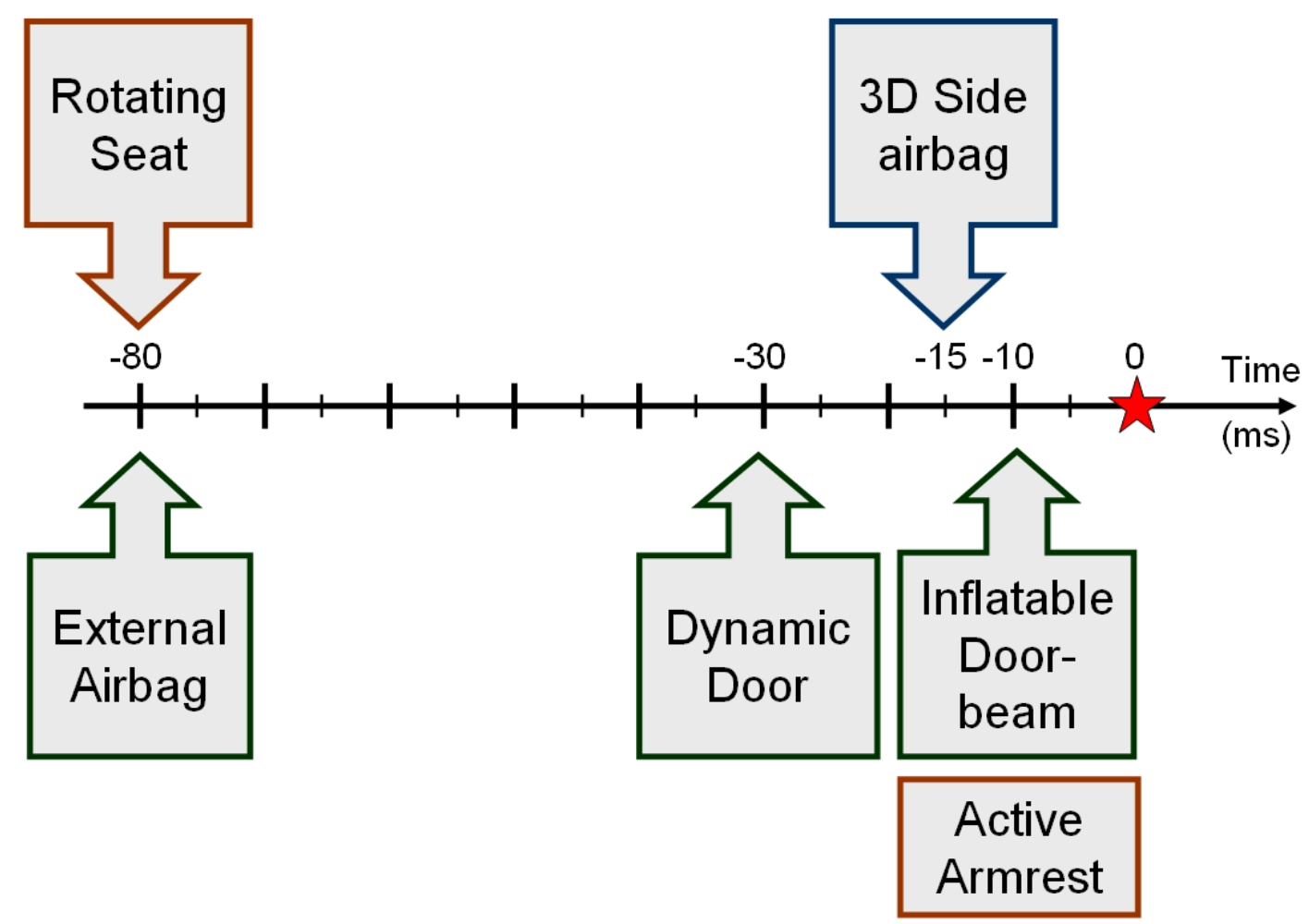

Figure 3. Triggering sequence of the 6 side impact systems

\section{Individual assessment for the different sub-systems}

Individual component tests in every sub-system were performed to evaluate the performance of each sub-system and to identify operating parameters like time needed for deployment or positioning. In addition, these tests provide the basis for creating finite element models of every sub-system.

As a second step, dynamic testing were performed for assessing the capability of each system to meet the specific objective for which it was intended (like energy absorption or create some additional clearance). Guided impactor tests, subsystem experiments or sled tests are examples of these tests, that also served to validate the finite element model of the system in the different performed iterations (Figure 4). 


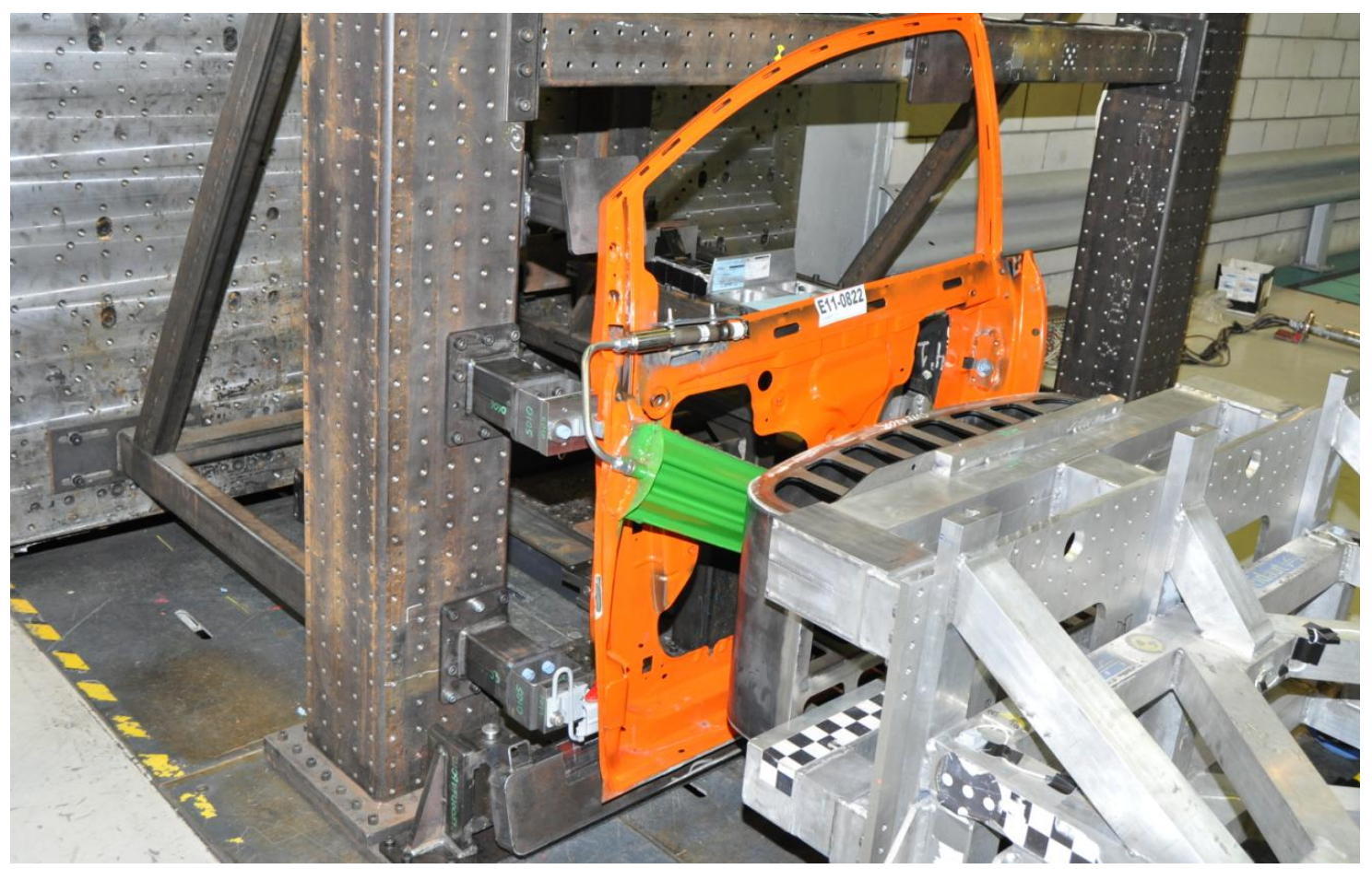

Figure 4. Example of dynamic test to assess the inflatable doorbeam

Finally, the sub-systems were validated separately and simultaneously in an initial series of sled tests with EuroSID-2 dummy. The goal for those sleds was to weigh the effect of the different countermeasures in terms of reduction of injury criteria according dummy readings.

The observed main effects of each system as well as the changes in the sled test configuration are represented in Table 1. A total of 24 sled test were performed. Analysis and results of these sled tests are not in the scope of this document.

\begin{tabular}{lccccl} 
& $\begin{array}{c}\text { Test } \\
\text { pulse }\end{array}$ & $\begin{array}{c}\text { Dummy } \\
\text { kinematics }\end{array}$ & $\begin{array}{c}\text { Distance to } \\
\text { the door }\end{array}$ & $\begin{array}{c}\text { Dummy } \\
\text { restraint }\end{array}$ & Sled adaptations for assessment of the system \\
\hline External airbag & $\mathbf{X}$ & - & - & - & Adaptation of the test pulse \\
\hline Inflatable door beam & $\mathbf{X}$ & - & - & - & Adaptation of the test pulse \\
\hline Active armrest & - & - & $\mathbf{X}$ & - & Increase of the distance prior to test \\
\hline Rotating seat & - & $\mathbf{X}$ & $\mathbf{X}$ & - & Inclusion of the system in the sled \\
\hline High-volume side airbag & - & - & - & $\mathbf{X}$ & Inclusion of the system in the sled \\
\hline Dynamic door & $\mathbf{X}$ & - & $\mathbf{X}$ & - & $\begin{array}{l}\text { Adaptation of the test pulse + Increase of the distance } \\
\text { prior to test }\end{array}$ \\
\hline
\end{tabular}

Table 1. Effect of each system

\section{Tests for vehicle Integration}

The first part of the integration was the creation of a full crash FEM model for the reference vehicle which integrated the validated FEM models of all the structural systems that affect the crash pulse (external airbag, active door and inflatable door beam). The obtained pulse was used in the sled tests. 
Additionally, virtual tests under different load conditions compared to the reference Euro NCAP test were carried out in this phase for assessing the robustness of the systems. Higher impact speed (60 $\mathrm{km} / \mathrm{h}$ instead of 50) and mass (1200 kg. instead of 950) as well as different impact angle $\left(60^{\circ}\right.$ instead of $90^{\circ}$ ) were virtually tested.

The next step was to define the reference test sled which is representative of the vehicle crash test, thus achieving a tool for comparison and evaluation. Given that the pre-crash structural countermeasures affect the rates of intrusion of the door and the boundary conditions of the vehicle, it was necessary to accordingly modify the reference sled pulse (representative of the reference crash in the sample vehicle without pre-crash countermeasures) and the initial conditions.

This sled with new pulses was used to evaluate the influence of structural systems in the biomechanical dummy values, as well as the behaviour of all of the systems developed previously, analyzing the influence of each one on the biomechanical values for the dummy. EuroSID-2 50\%ile and SID-IIs 5\% ile dummies were used in sled tests for assess the effect in different occupants.

In the final phase an optimization process for all sub-systems and activation parameters were performed in the full scale crash test for validation.

\section{Final vehicle testing involving all countermeasures simultaneously.}

All countermeasures were integrated simultaneously in four prototype passenger car. Table 2 reproduces the test matrix configuration.

\begin{tabular}{lcccl} 
& Dummy & Vehicle & $\begin{array}{c}\text { Speed } \\
(\mathbf{k m} / \mathbf{h})\end{array}$ \\
\hline Reference & ES-2 & SEAT Altea XL & 50 & Reference test without Pre crash countermeasures \\
\hline Pre-Crash $\mathbf{1}$ & ES-2 & SEAT Altea XL & 50 & First crash test with all pre crash countermeasures \\
\hline Pre-Crash $\mathbf{2}$ & ES-2 & SEAT Altea XL & 50 & Progressive triggering of seat actuators $(-80$ to $-55 \mathrm{~ms})$ \\
\hline Pre-Crash $\mathbf{3}$ & ES-2 & SEAT Altea XL & 50 & Progressive triggering of seat actuators (-80 to $-55 \mathrm{~ms})$ (Repeatability) \\
\hline Pre-Crash $\mathbf{4}$ & ES-2 & SEAT Altea XL & $\mathbf{6 0}$ & Progressive triggering of seat actuators (-80 to $-55 \mathrm{~ms})$. Higher test speed \\
\hline
\end{tabular}

Table 2. Crash test matrix

In order to assess the biomechanical effect of those systems, the obtained dummy values were compared with a reference side crash test following the Euro NCAP testing protocol and using the same sample vehicle without any additional countermeasure.

The potential of the presented countermeasures under more severe conditions was also evaluated through one crash test at $60 \mathrm{~km} / \mathrm{h}$. As reported by Welsh et al, around $80 \%$ of MAIS 2+ injuries were found to occur in impacts with a collision severity (as measured by delta-V) greater than that which occurs in a $50 \mathrm{~km} / \mathrm{h}$ crash test [7], in the same study, average mass of bullet or striking vehicles in the data was found to be $1250 \mathrm{~kg}$. In the present work, a $1200 \mathrm{~kg}$ barrier mass and $60 \mathrm{~km} / \mathrm{h}$ speed test was performed trough FEM-simulation.

FEM simulations under different conditions (different speed and mass of the barrier, impact angle, occupant sizes) were also performed for assessing the systems robustness in a previous phase.

\section{Equipment and facilities}

A MTS 888 Horizontal Crash Simulator (reverse accelerating sled test system) with hydraulically controlled movement of the sled for the whole pulse duration and programmable acceleration profiles and a full-scale crash test track from MESSRING Systembau MSG at CIDAUT in Valladolid, Spain, were used to perform the sled and crash tests. EuroSID-2 50\%ile and SID-IIs 5\%ile dummies were 
used for sled and full scale crash test. All tests were filmed using high-speed digital cameras. Pamcrash ${ }^{\circledR}$ software was used for FEM-analysis.

\section{RESULTS}

The results presented correspond to the dummy measurements recorded at the crash tests involving vehicles with and without countermeasures. Crash FEM simulation results and sub-systems sled tests results are not reported in this manuscript.

The biomechanical dummy values recorded in crash tests at $50 \mathrm{~km} / \mathrm{h}$ show a substantial reduction compared to the values obtained in the reference test according to the Euro NCAP side impact barrier test. This improvement was mainly focused in the thoracic area (lower rib deflection was reduced by $72 \%$ ), in the abdomen (the Peak Force was reduced by 63\%), and in the pelvis area (Peak Force) the reduction was $41 \%$. A summary of crash test results is reproduced in Table 3.

The recorded Force values in the shoulder are slightly higher than in the reference test. The different size of the airbag and the loading process (earlier in time) can explain this effect.

\begin{tabular}{|c|c|c|c|c|c|c|c|}
\hline & Units & $\begin{array}{c}\text { Reference } \\
(50 \mathrm{~km} / \mathrm{h})\end{array}$ & $\begin{array}{c}\text { Pre-Crash } 1 \\
(50 \mathrm{~km} / \mathrm{h})\end{array}$ & $\begin{array}{c}\text { Pre-Crash } 2 \\
(50 \mathrm{~km} / \mathrm{h})\end{array}$ & $\begin{array}{c}\text { Pre-Crash } 3 \\
(50 \mathrm{~km} / \mathrm{h})\end{array}$ & $\begin{array}{c}\text { Pre-Crash } 4 \\
(60 \mathrm{~km} / \mathrm{h})\end{array}$ & Limit * \\
\hline Shoulder Fx & $\mathrm{kN}$ & 0,12 & 0,42 & 0,25 & 0,40 & 0,47 & - \\
\hline Shoulder Fy & $\mathrm{kN}$ & 0,47 & 0,68 & 0,64 & 0,67 & 0,78 & - \\
\hline Upper Rib compression & $\mathrm{mm}$ & 13,80 & 4,90 & 5,10 & 5,10 & 6,30 & 22,00 ** \\
\hline Upper Rib VC & $\mathrm{m} / \mathrm{s}$ & 0,09 & 0,01 & 0,01 & 0,02 & 0,03 & 0,32 ** \\
\hline Middle Rib compression & $\mathrm{mm}$ & 11,90 & 3,60 & 3,00 & 4,00 & 4,40 & 22,00 ** \\
\hline Middle Rib VC & $\mathrm{m} / \mathrm{s}$ & 0,05 & 0,01 & 0,01 & 0,01 & 0,02 & 0,32 ** \\
\hline Lower Rib compression & $\mathrm{mm}$ & 17,50 & 5,20 & 4,90 & 5,60 & 6,50 & 22,00 ** \\
\hline Lower Rib VC & $\mathrm{m} / \mathrm{s}$ & 0,09 & 0,01 & 0,01 & 0,01 & 0,02 & 0,32 ** \\
\hline Backplate Load & $\mathrm{kN}$ & 0,17 & 0,11 & 0,13 & 0,10 & 0,27 & 1,00 \\
\hline Abdomen Force APF & $\mathrm{kN}$ & 0,44 & 0,27 & 0,16 & 0,23 & 0,38 & 1,00 \\
\hline Pelvis Force PSPF & $\mathrm{kN}$ & 1,15 & 0,74 & 0,67 & 0,65 & 1,22 & 3,00 \\
\hline Spine T12Fy & $\mathrm{kN}$ & 0,66 & 0,61 & 0,56 & 0,69 & 0,98 & 1,50 \\
\hline Spine T12Mx & $\mathrm{Nm}$ & 59,10 & 82,30 & 66,20 & 74,50 & 97,20 & 150,00 \\
\hline
\end{tabular}

* Higher performance limit acording Euro NCAP Assessment protocol for adult occupant protection V. 5.1

** $5 \%$ risk of injury AIS3+ [7]

Table 3. Summary of crash test results

\section{Shoulder}

Maximum forces in the shoulder are slightly higher than the reference crash (from 0,12 to $0,25 \mathrm{kN}$ and 0,47 to 0,64 kN Approximately), and are produced earlier in time (Figure 5). This effect occurs primarily in Fx and Fy, and these forces are in all cases in very low levels (below $1 \mathrm{kN}$ ) (Fig 5). 

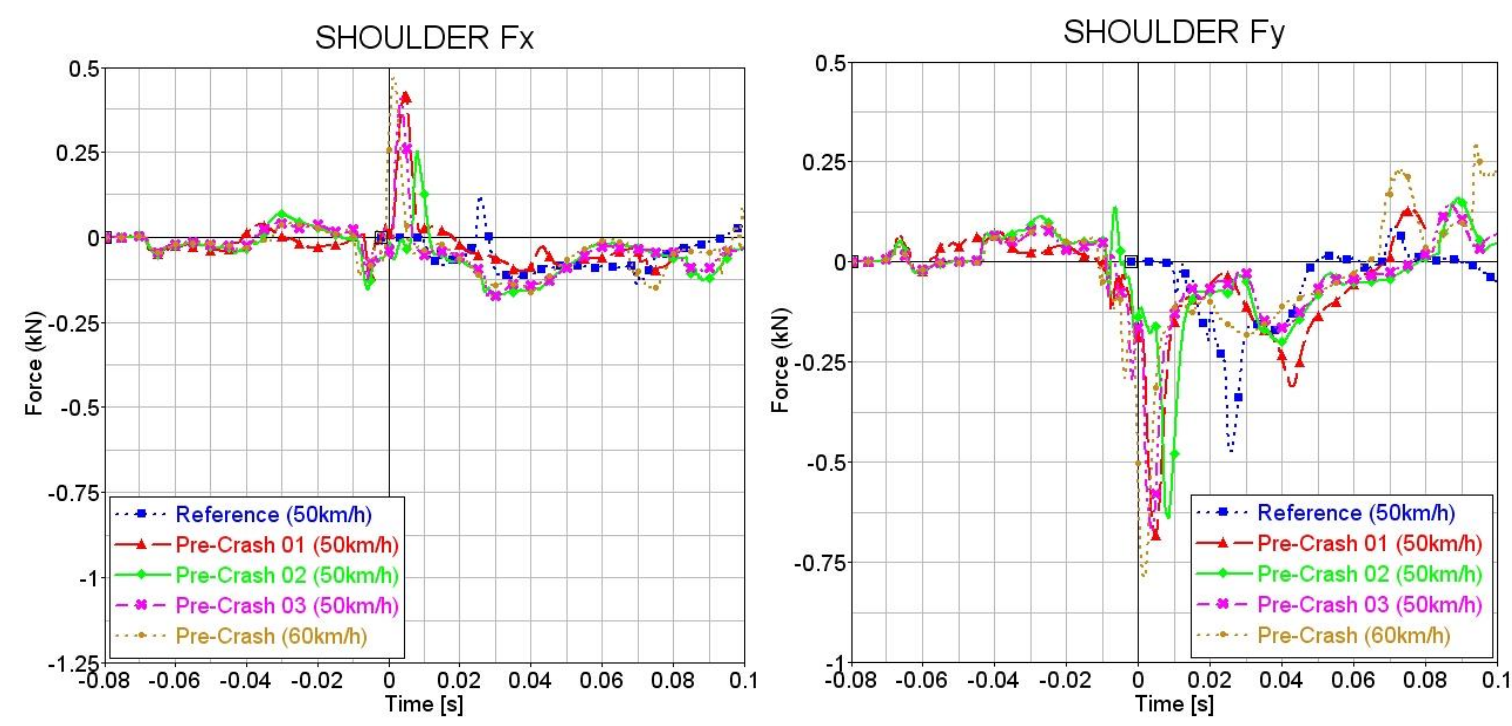

Figure 5. Shoulder forces

\section{Spine T12}

Maximum values of forces and moments on the T12 are similar to those registered in the reference test, however the movement of the seat before the collision causes an increase in these values of around $0,3 \mathrm{kN}$ and $70 \mathrm{Nm}$ respectively before the impact occurred (Fig. 6).
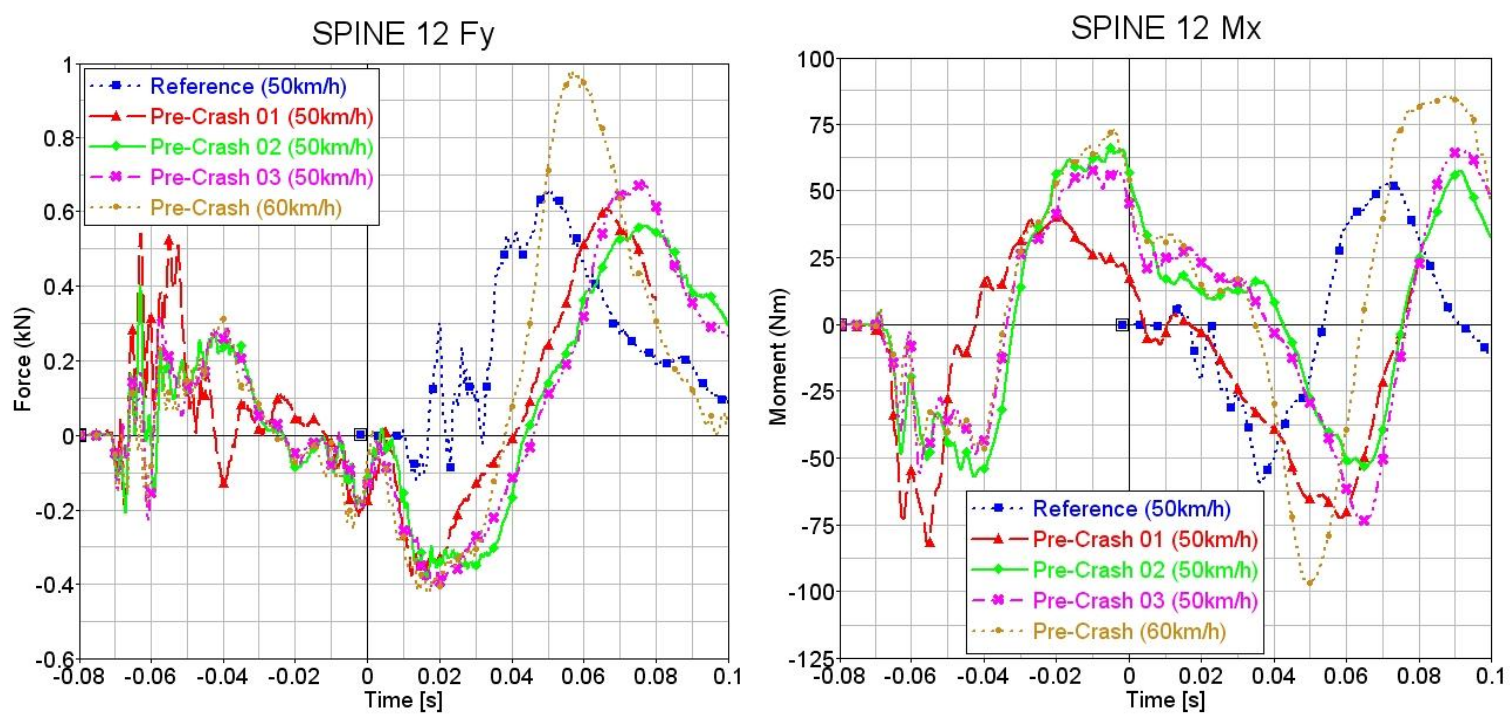

Figure 6. Spine T12 Forces and moments

\section{Chest}

The chest deflection values recorded are in all tests substantially lower than those obtained in the reference crash. The reductions are the order of $70 \%$ (Fig. 7). About $40 \mathrm{~ms}$ prior to impact occurs a deflection of 1-2 mm which is due to the effect of the movement of the tilting seat backrest on the dummy. The same effect and reduction of maximum values was observed in Viscous Criteria (VC) measurements. 

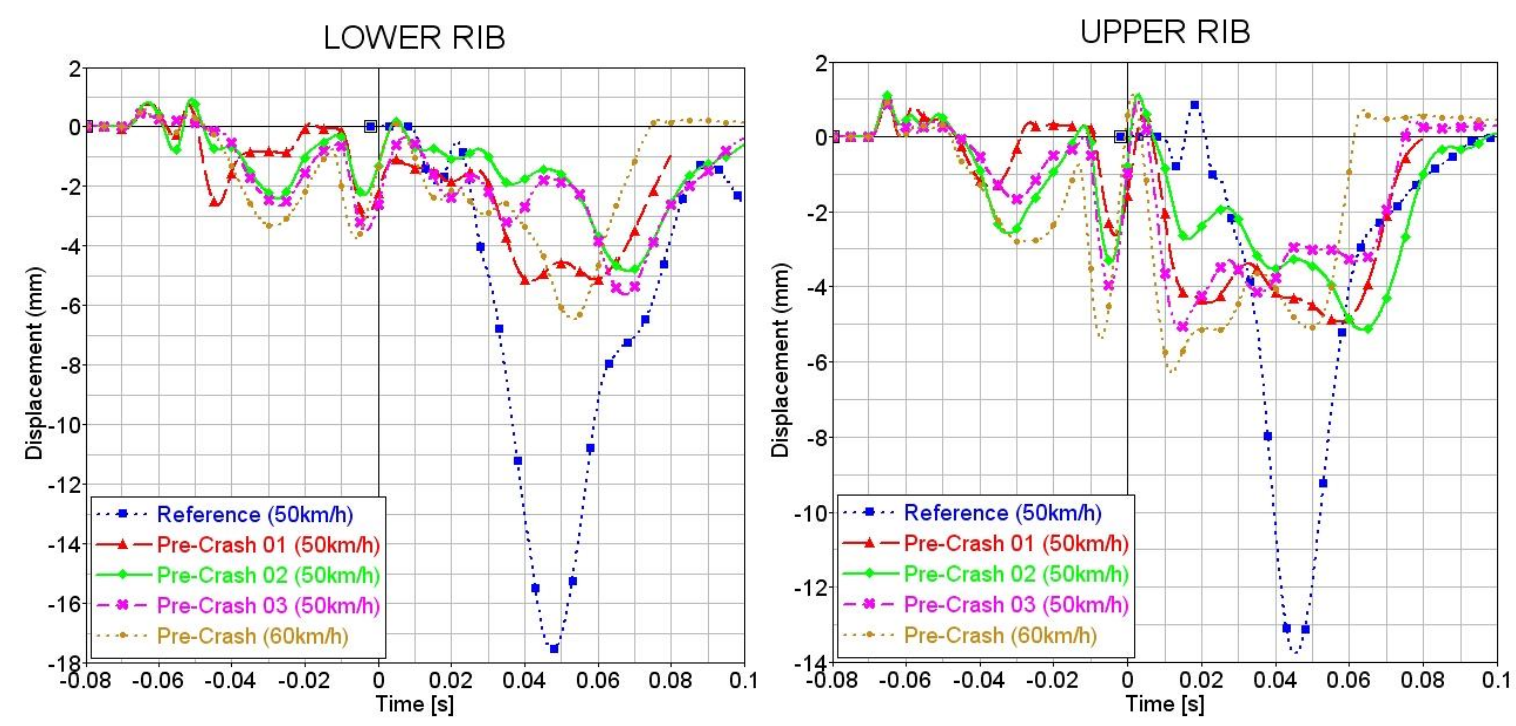

Figure 7. Chest deflection

\section{Abdomen}

The abdominal force (APF) reduces its value by 40 to $60 \%$ relative to the reference test. As observed in the chest, a small force was observed in the $40 \mathrm{~ms}$ prior to impact due to interaction between the abdomen and the seat (Fig. 8). This interaction force is negligible compared to the value recorded during the impact. The rear load cell of the abdomen, more influenced by the seat on impact, reaches the same value as the reference tests. The other two load cells (middle and front) get substantially lower values than the reference tests.
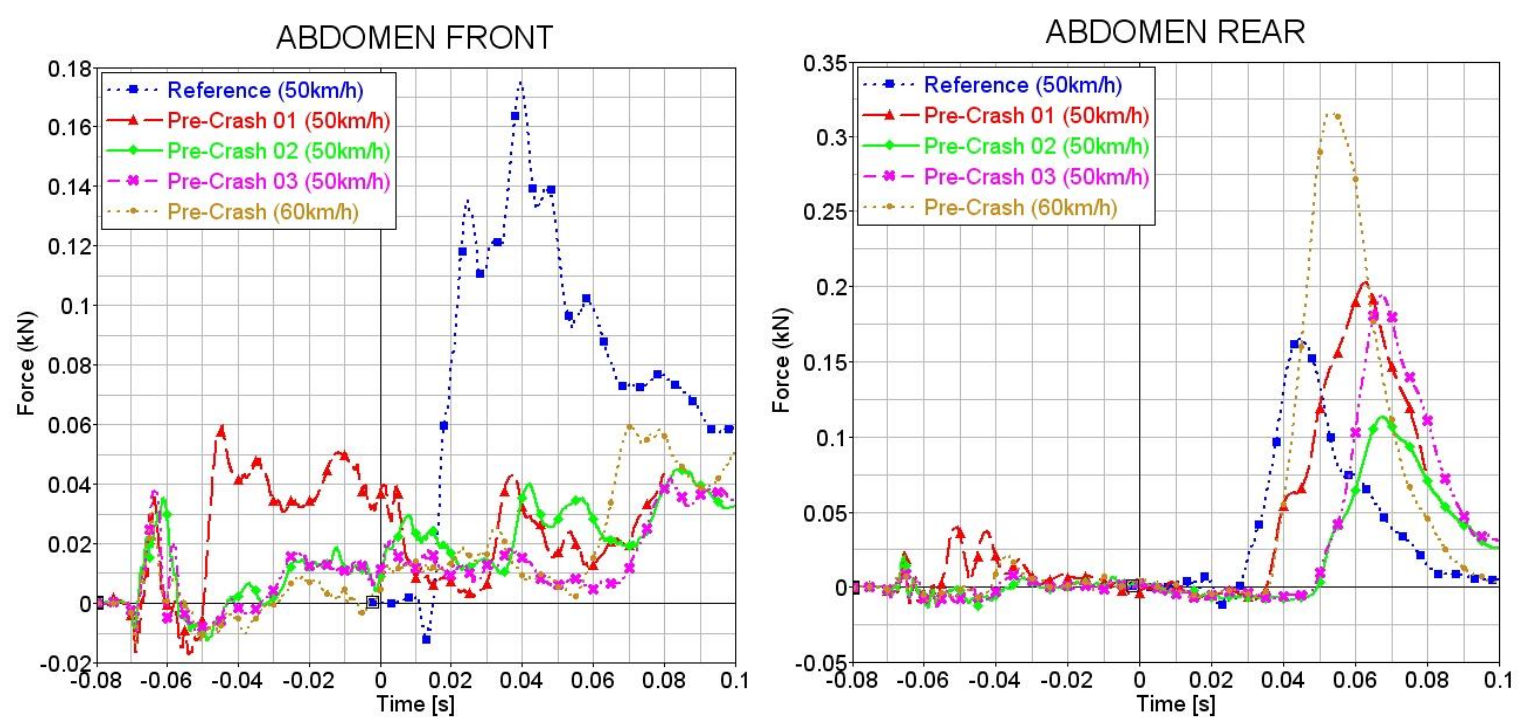

Figure 8. Abdomen forces

\section{Pelvis}

The peak force measured in the pelvis (PSPF) reduces its maximum value by about $30 \%$ respect to the reference test. As observed in the T12 values, around $60 \mathrm{~ms}$ before the impact a load appears in the pelvis due to the seat movement. The level of this initial force is half the level of the impact. Nevertheless, this effect is more pronounced in the acceleration traces (Fig. 9) where the values recorded at this early stage nearly equal to the maximum values measured during the impact phase. 

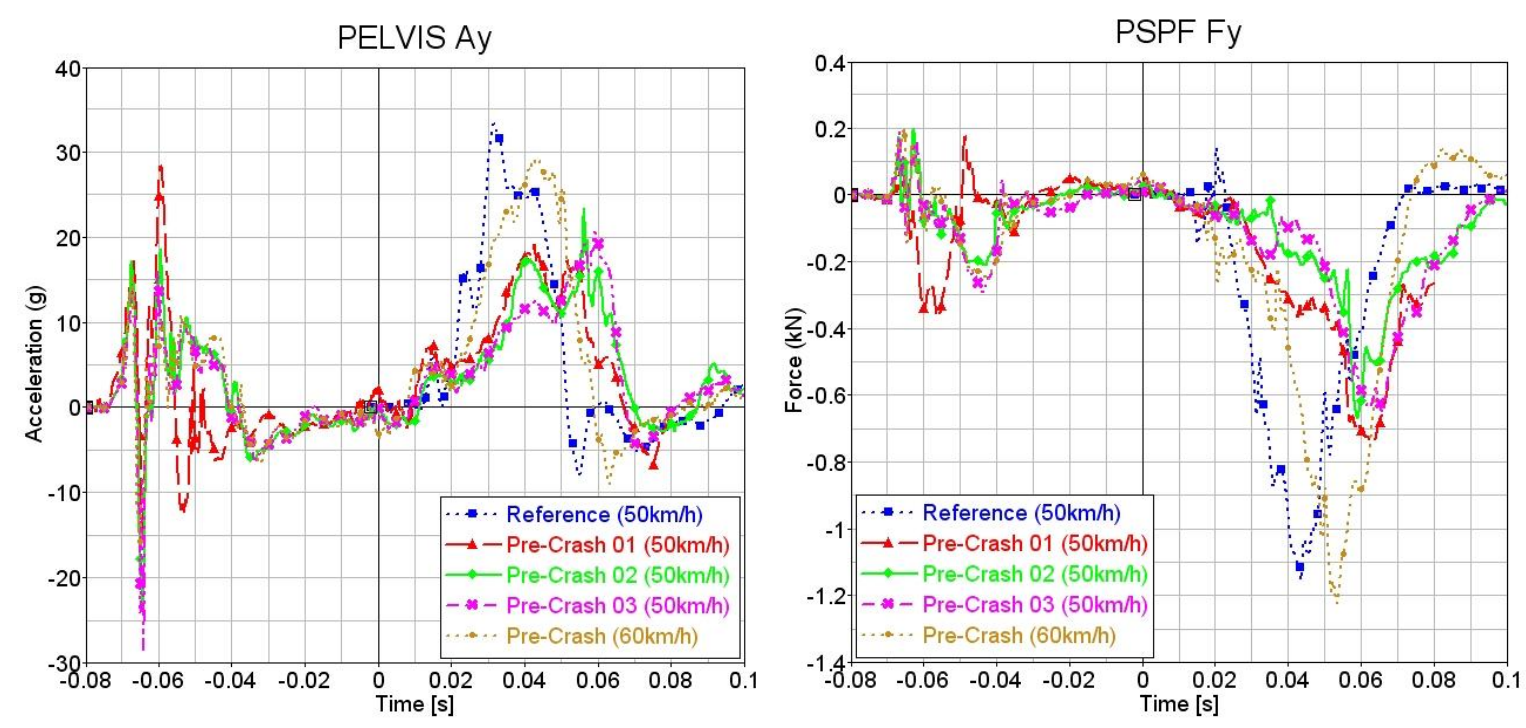

Figure 9. Pelvis acceleration and Force

\section{DISCUSSION}

Maximum forces in the shoulder were slightly higher than the reference crash, and were produced earlier in time (around $0 \mathrm{~ms}$ instead of $25 \mathrm{~ms}$ in the reference test). This could be explained by the greater width of the side airbag in the shoulder area and the earlier firing time. Even if this biomechanical parameter is currently not assessed in the Euro NCAP side impact protocol, peak forces must be taken into account due to its relationship with injury risk [9].

Rib deflection values were in all the cases, including the test at $60 \mathrm{~km} / \mathrm{h}$, lower than in the reference test, remaining always in a very low level (around $5 \mathrm{~mm}$ deflection). To increase the distance between door and occupant, as well as early restraint of ribcage with large airbags were found in the literature to produce this favourable effect [10], [11], [12], [13]

A detailed analysis of the effect of systems in the vehicle structure in terms of intrusion velocities could not be carried out, due to the noise registered in the signal of the accelerometers mounted in the door generated by the pyrotechnic systems and the fast movement of the dynamic door. Qualitatively a change in the pattern of deformation can be observed, due to the inclusion of the three systems that have structural influence (External airbag, dynamic door and inflatable doorbeam) that must be taken into account if future studies on these systems are performed.

There is a slight increase in the measured values of T12 (force Fy and Mx). The fast rotation of the base of the seat causes an increase of the initial values on the T12 (force and moment) due to the stronger effect in the movement of the pelvis than in the torso of the dummy. The effect can also be seen in the pelvis and spine accelerations. For minimising that effect, the 8 pyrotechnic actuators located at the seat were fired progressively between -80 and $-55 \mathrm{~ms}$ in the tests referred as pre-crash2, 3 and 4. A reduction of the loads prior to the crash with respect to the test pre-crash1 (were all actuators were fired at $-80 \mathrm{~ms}$ ) can be seen in the spine and pelvis curves. In all cases the biomechanical dummy values recorded prior to the crash were lower than that correspondent to the loading during the crash phase.

The use of gas generators (inflators) as a cost- and weight-efficient method to generate overpressure can be found in the literature for other applications than side crash protection with important benefits for crash performance [14]. In the present research, gas generators are also used for creating movement in the seat base and in the door. Progressive firing times and adaptation of the power of the actuators were necessary for reduce the observed effect in dummy kinematics prior to crash. 


\section{CONCLUSIONS}

Pre-crash systems are being discussed mostly for frontal impact [15], being detection technologies and Automated Emergency Braking Systems in the State of the art. The present work shows the potential of these systems in the event of side impact in terms of improved biomechanical dummy values, even when starting from a reference vehicle with a very good performance under Euro NCAP side impact assessment.

Dummy results were generally improved, and particularly in chest deflection, which is a clear indicator of injury risk according to the epidemiologic studies. The obtained 4-6 mm chest deflection values are far below the injury levels according the scientific and technical literature. A maximum rib deflection of $21 \mathrm{~mm}$ is associated $25 \%$ risk ( $44 \mathrm{~mm}, 50 \%$ risk) of sustaining AIS 3+ injuries [16].

This paper demonstrates that there is still room for reducing the sustained injuries in side crash. A suitable combination of active and passive countermeasures have shown to be an appropriate strategy.

\section{AKNOWLEDGEMENTS}

The authors would like to thank the Centro para el Desarrollo Tecnológico Industrial (CDTI) for funding this research project. The presented research was part of the ADAPTA project, included in the CENIT spanish research program under identification number CEN 20081031. We are also in debt with Fundación CIDAUT and the project partners TRW, SEAT, Grupo Antolin, Gestamp, Anafocus, Elecnor Deimos and Magom for their cooperation.

We are also deeply grateful to Greg Shaw, Senior Scientist at the Center for Applied Biomechanics (University of Virginia), for his scientific contribution reviewing the paper.

\section{REFERENCES}

[1] SW. Rouhana, ME. Foster, Lateral Impact- An Analysis of the Statistics in the Ncss. Stapp Car Crash Conference Proceedings, Paper 851727, 1985

[2] P. Thomas, R. Welsh, E. Lenguerrand, G. Vallet, D. Otte, J. Strandroth, Priorities for Enhanced Side Impact Protection in Regulation 95 Compliant Cars, 21th International Technical Conference on the Enhanced Safety of Vehicles (ESV), Stuttgart, NHTSA, 2009

[3] M. Bedard, GH. Guyatt, MJ. Stones, JP. Hirdes, The independent contribution of driver, crash, and vehicle characteristics to driver fatalities, Accident Analysis and Prevention, 2002, 34(6): 717-727.

[4] R. Welsh, A. Morris, A. Hassan, Injury Outcomes In Side Impacts Involving Modem Passenger Cars, 20th International Technical Conference on the Enhanced Safety of Vehicles (ESV), Lyon, NHTSA, 2007.

[5] R. Engel, Social and cultural variables in accident causation, TRACE Project WP3 report Task 3.2, (2008)

[6] E. Zimmerman, Adaptive protection system for side impact accidents, 18. Aachener Kolloquium Fahrzeug- und Motorentechnik, Aachen, RWTH, 2009.

[7] R. Welsh, A. Morris, P. Thomas, J. Lenard, J. Barnes, D. Otte, Car to car struck side impacts - a comparison between European accident data and directive 96/27/EC, IRCOBI Conference proceedings, pp. 115-128, York (UK), 2009

[8] R. Lowne, E. Janssen, Thorax injury probability estimation using production prototype EUROSID, ISO/TC22/SC12/WG6 document N302.

[9] C. Arregui-Dalmases, E. del Pozo, S. Duprey, FJ. Lopez-Valdes, A. Lau, D. Subit, R. Kent, A Parametric Study of Hard Tissue Injury Prediction Using Finite Elements: Consideration of Geometric Complexity, Subfailure Material Properties, CTThresholding, and Element Characteristics, Traffic Injury Prevention, 2010, 11 (3): 286-293

[10] Y. Deng, J. Wang, J. Peng, S. Kulkarni, An Analytical Study of Side Airbag Designs for TTI Reduction in a Large Size Car, SAE Technical Paper 982322, 1998, doi:10.4271/982322

[11] NHTSA Technical Report, An Evaluation of Side Impact Protection, DOT HS 810748 January 2007 
[12] S. Schneider, M. Niwa, T. Koyama, T. Tanase, Y. Sato, M. Sakamoto, M. Asaoka, Effectiveness of thorax \& pelvis side airbag for improved side-impact protection, $19^{\text {th }}$ International Technical Conference on the Enhanced Safety of Vehicles (ESV), Washington DC, NHTSA, 2005

[13] Y. Page, P. Thomas, V. Herve, A. Kirk, The effectiveness of side airbags in preventing thoracic injuries in Europe, Expert Symposium on Accident Research, Hannover, 1-2 September 2006

[14] Pipkorn B., Lundström J., Ericsson M., Improved car occupant safety by expandable A-Pillars, International Journal of Crashworthiness, 201217 (1): 11-18.

[15] J. Carlin, C. Birdsong, P. Schuster, W. Thompson, D. Kawano, Evaluation of Cost Effective Sensor Combinations for a Vehicle Precrash Detection System, Commercial Vehicle Engineering Congress and Exhibition, Chicago, SAE, 2005

[16] S. Kuppa, Injury criteria for side impact dummies, National Transportation Biomechanics Research Center, National Highway Traffic Safety Administration, 2004 